\section{El dengue, un problema creciente de salud en las Américas}

\author{
Gustavo Kourí1
}

1 Instituto de Medicina Tropical, Autopista del Mediodía $\mathrm{km}$ 3fi, La Lisa, Ciudad de La Habana, Cuba. Correo electrónico: gkouri@ipk.sld.cu
El dengue es un reto para la salud pública en el mundo. Más de $2500 \mathrm{mi}-$ llones de personas - es decir, más de dos quintas partes de la población mundial - viven en zonas en riesgo de dengue y más de 100 países han informado de la presencia de esta enfermedad en su territorio (1). La Región de las Américas ha sido una de las más afectadas por el dengue y su forma más grave, el dengue hemorrágico.

Esta enfermedad, causada por el virus del dengue y transmitida por mosquitos del género Aedes, fue descrita por primera vez en 1780 por Benjamin Rush, en Filadelfia, Pensilvania, Estados Unidos de América. Hasta el momento se han descrito cuatro serotipos de este virus que circulan principalmente en países del sudeste asiático, del Pacifico occidental y de América Latina y el Caribe, por lo que la enfermedad se considera tropical.

La primera epidemia conocida de dengue en territorio americano ocurrió en el siglo XVIII. A partir de entonces, esta enfermedad ha afectado a casi todos los países de la Región, aunque en la actualidad el mayor número de casos se concentra en América Latina y el Caribe.

Las particularidades del cuadro clínico, la gravedad de la enfermedad y la magnitud de las epidemias dependen de las características del vector, del virus y de la persona infectada (factores microdeterminantes). Influyen también el medio ambiente, el clima y el nivel sanitario, principalmente en las zonas urbanas, así como algunos factores sociales y económicos (factores macrodetermiantes). El debilitamiento de los sistemas de salud pública debido a la privatización desmedida y la falta de programas sostenibles para el control del vector han llevado a que el dengue se convierta en una enfermedad endémica al sur del Río Bravo (1-3), a tal punto que en la actualidad los únicos países latinoamericanos donde el dengue no es endémico son Chile, Cuba y Uruguay.

El dengue hemorrágico se describió en el sudeste asiático en 1960 después de las epidemias de Manila, Filipinas, y Bangkok, Tailandia, aunque algunos estudios retrospectivos indican que la primera epidemia de esta forma grave de dengue ocurrió en Grecia en 1928, donde provocó gran mortandad (4). La primera gran epidemia de dengue hemorrágico en América ocurrió en Cuba en 1981, con miles de enfermos y 158 fallecidos. Aunque se logró controlar en poco más de cuatro meses - a un costo de más de 103 millones de dólares estadounidenses-y la Región no tuvo nuevas epidemias durante siete años, la circulación simultánea de varios serotipos en un mismo país (hiperendemia) ha perpetuado el riesgo, existente aún, de nuevas epidemias de esta forma grave de dengue.

La Organización Mundial de la Salud (OMS) y la Organización Panamericana de la Salud (OPS) han establecido cuatro elementos básicos o principios que son necesarios para controlar el dengue $(2,3)$. Ellos son:

- $\quad$ la voluntad política de los gobiernos

- la coordinación intersectorial

- la participación activa de la comunidad

- $\quad$ el fortalecimiento de las leyes sanitarias nacionales 
La nueva generación de programas de prevención y control del dengue en América respalda estos principios, complementados con acciones encaminadas a lograr la adecuada vigilancia y el control de la transmisión con un enfoque ecosistémico (3). Esto significa que se sabe bien lo que hay que hacer; el reto consiste en hacerlo de forma integrada y sostenible. Sin embargo, en la gran mayoría de los países de la Región aún no se aplican a cabalidad estos principios y no se cuenta con programas de control preventivos, integrados y sustentables.

Las autoridades sanitarias nacionales deben reaccionar de inmediato ante el riesgo de epidemias de dengue, sin esperar a que ocurran muertes por dengue hemorrágico y antes de que se sienta la presión de la población y de los medios masivos de comunicación. La voluntad política debe manifestarse mediante campañas intensivas de control del vector, tanto preventivas como durante las epidemias, ya que son la única opción que tenemos en la actualidad para controlar la transmisión de la enfermedad. Aunque se han desarrollado varias vacunas candidatas contra el dengue, aún no se cuenta con una vacuna capaz de proteger a la población en riesgo.

El sector de la salud debe desempeñar un papel protagónico en la dirección de las campañas de lucha antivectorial, la vigilancia epidemiológica para la detección temprana de los brotes y la capacitación del personal médico para lograr un diagnóstico oportuno y certero que evite muertes. Sin embargo, numerosas actividades, tales como el suministro de agua potable, su adecuado almacenamiento y la disposición de residuos líquidos y sólidos, no dependen de las estructuras del sistema de salud. En muchas ocasiones, estos servicios son privados $\mathrm{y}$, aunque las entidades responsables obtienen cuantiosas ganancias, no participan en las acciones dirigidas a controlar la transmisión del dengue y de otras enfermedades relacionadas con la higiene ambiental. Sin embargo, su participación es factor determinante para reducir los focos de cría del vector, la mayoría de los cuales obedecen a la acción del hombre. Los gobiernos, las entidades encargadas de estos servicios, las ONG, las iglesias, en fin, todas las instancias de la sociedad deben participar en los programas de prevención del dengue.

A pesar de que la participación comunitaria es un elemento clave en la lucha contra el dengue, es difícil que una comunidad pobre cuya población tiene un bajo nivel cultural y educacional se preocupe por el control del vector cuando su prioridad es luchar por su subsistencia. En la situación actual de nuestra Región, esta realidad constituye un reto para el control del mosquito vector, y por tanto, de la enfermedad.

Un análisis somero de la situación epidemiológica actual refleja que la Región no se encuentra preparada aún para evitar nuevas epidemias de dengue. Aunque todavía no existen condiciones para erradicar el vector, es posible aplicar medidas de control intensivas que eviten las epidemias. Para ello es necesario que los sistemas de salud pública fortalezcan sus vínculos con otros sectores de la sociedad, como se expresa en el proyecto Impacto Conductual Comunitario (COMBI) promovido por la OMS y la OPS (5). La participación comunitaria en esta tarea es esencial y aunque la responsabilidad debe mantenerse en las manos de las autoridades sanitarias, debe lograrse una amplia participación de todas las instancias, desde los jefes de estado hasta los estratos sociales más alejados del poder. Si bien los ministerios de salud deben desempeñar un papel determinante en las actividades de orientación, la educación de la población y el control de los programas nacionales, es preciso insistir en que la participación responsable de la comunidad puede y debe contribuir a eliminar los principales criaderos del vector, ya que están ligados al hábitat del ser humano y son producto de su actividad. 
Los gobiernos deben seguir las recomendaciones de la OMS y la OPS expresadas en varias de sus resoluciones además de reforzar y aplicar adecuadamente las leyes sanitarias relacionadas directa o indirectamente con el control de los vectores. Es necesario tomar conciencia de que si las grandes sumas de dinero que se gastan cuando ocurren epidemias se invirtieran en eliminar o atenuar los macrofactores determinantes correspondientes, se podrían evitar o atenuar muchas epidemias. Lograr este objetivo es el gran reto de la salud pública en América. Si se cumplen los principios de control propuestos por los organismos internacionales de la salud, se podrá ganar con seguridad la batalla contra el dengue.

\section{REFERENCIAS}

1. Guzmán MG, Kourí G. Dengue: an update. Lancet Infect Dis. 2002;2:33-42.

2. Pan American Health Organization. Dengue and dengue hemorrhagic fever in the Americas: guidelines for prevention and control. Washington, D.C.: PAHO; 1994. (Scientific Publication No. 548).

3. Organización Panamericana de la Salud. Nueva generación de programas de prevención y control del dengue en las Américas. Washington, D.C.: OPS; 2002. (OPS/HCP/HCT/206/02).

4. Halstead SB, Papaevangelou G. Transmission of dengue 1 and 2 viruses in Greece in 1928. Am J Trop Med Hyg. 1980;29:635-7.

5. Parks W, Lloyd L. Planificación de la movilización y comunicación social para la prevención y el control del dengue. Guía paso a paso. Ginebra: Organización Mundial de la Salud; 2004. 